\title{
Update on Hepatitis B Virus Infection: Focus on Treatment
}

\author{
Stephanos J. Hadziyannis* \\ Liver Unit and its Molecular Biology Laboratory, National and Kapodistrian University of Athens, Evgenidion Hospital of Athens, \\ Athens, Greece
}

\begin{abstract}
This review article is an update of the current treatment strategies available for chronic hepatitis B. In addition to achieving on-therapy clinical remission and suppression of HBV replication without resistance, the ultimate goal of therapy is the development of sustained remission and $\mathrm{HBsAg}$ loss after discontinuation of treatment. This is the closest possible to cure outcome for hepatitis B virus (HBV) infection. These goals can be achieved by response-guided courses of pegylated interferon (peg-IFN)-alpha at rates higher than $30 \%$, both in hepatitis B e antigen (HBeAg)positive and $\mathrm{HBeAg}$-negative patients. Review of the data regarding discontinuation of long term NA treatment in HBeAg-negative patients revealed that stopping such therapy is safe with high rates of sustained off treatment responses that appear to be immunologically induced. Decreasing hepatitis B surface antigen ( $\mathrm{HBsAg}$ ) titers under therapy to $<500$, particularly $<100 \mathrm{IU} / \mathrm{mL}$, and adding a course of pegIFN to ongoing long term nucleos(t)ide analogue (NA) therapy increase the percentage of sustained responses following discontinuation of NA treatment.

(C) 2014 The Second Affiliated Hospital of Chongqing Medical University. Published by XIA \& HE Publishing Ltd. All rights reserved.
\end{abstract}

\section{Introduction}

In the mid-1960s, Baruch Blumberg along with a group of American investigators ${ }^{1}$ discovered and described the socalled Australia Antigen, a protein that was eventually demonstrated to be the envelope protein of the hepatitis $B$ virus (HBV). ${ }^{2-4}$ This protein was properly renamed in the 1970 s to hepatitis B surface antigen (HBsAg). ${ }^{5,6}$ Since then, our understanding of all aspects of HBV infection has grown, ${ }^{7-11}$ but chronic liver disease caused by this virus has proven to be a major and ongoing health problem world-

Keywords: HBV; Treatment; Chronic hepatitis; Interferon; NA discontinuation. Abbreviations: 3TC, lamivudine; AASLD, American Association for the Study of Liver Diseases; ADV, adefovir; ALT, alanine aminotransferase; APASL, Asian and Pacific Associations for the Study of the Liver; cccDNA, covalently closed circular DNA; CHB, chronic hepatitis B; EASL, European Association for the Study of Liver; ENT, entecavir; HBV, hepatitis B virus; HBeAg, hepatitis B e antigen; HBsAg, hepatitis B surface antigen; HCC, hepatocellular carcinoma; HIV, human immunodeficiency virus; IFN, interferon; IP-10, IFN- $\gamma$-inducible protein 10; NAs, nucleos(t)ide analogues; TDF, tenofovir; peg-IFN, pegylated interferon. Received: 25 August 2014; Revised: 21 September 2014; Accepted: 21 September 2014

DOI: $10.14218 / \mathrm{JCTH} .2014 .00026$.

* Correspondence to: Stephanos J. Hadziyannis, 4 Dirrachiou Str., Athens 15669 Greece. Tel: +30-2106516807, Fax: +30-2106543299, E-mail: hadziyannis@ath. forthnet.gr wide. ${ }^{11-13}$ Hepatitis $B$ represents the most frequent cause of mortality from cirrhosis and hepatocellular carcinoma (HCC) relative to any other viral and non-viral infection of the liver. ${ }^{12}$

Multiple breakthrough discoveries regarding HBV infection have accumulated over the years, clarifying the complex mode of HBV replication as the development of a replication capable minichromosome of covalently closed circular DNA (cccDNA) located in the nuclei of infected hepatocytes, that shed new light on the expression in liver of various HBV components, proteins, and replicative intermediates as well as on the integration of HBV DNA into the genome of hepatocytes during the course of the infection. Concurrently, the development of sensitive virological, serological, and other laboratory methods has made possible the detection and quantification of HBV DNA and various HBV proteins in peripheral blood and extrahepatic sites. These advances have contributed to understanding the natural clinical course of chronic HBV infection and its responsiveness to developing treatment modalities. There is also important new evidence regarding viral heterogeneity of HBV genotypes and their impact on the course of infection, pathogenetic mechanisms of liver necroinflammation and fibrosis, and response to treatment. These topics have been reviewed extensively in the world literature, and some relevant and recent review articles have been selected and are herein referred. ${ }^{6,8,9,11,12,14-18}$

Here, we present an update on HBV infection with a focus on its therapy as well as a review on the evolution of HBV therapy from the 1980s with the launch of conventional interferon (IFN) alpha $^{5}$ to data published up to year 2014 on the proper use and efficacy of the first line nucleos(t)ide analogues (NAs) entecavir (ENT) and tenofovir (TDF) and pegIFN alpha $2 \mathrm{a}$ (peg-IFN). The treatment guidelines for hepatitis $B$ with these compounds were last published by the American (AASLD), the European (EASL), and the Asian and Pacific (APASL) Associations for the Study of the Liver in 2009, 2012, and 2012, respectively. ${ }^{19-21}$ Since then, HBV treatment has progressed even further, and several suggestions have been made to modify and improve therapeutic strategies. In this context, it is important to note that approximately $40 \%$ of the HBV articles published in 2013 and 2014 were about its treatment.

With the use of first line treatments NAs, ENT and TDF, the goal of long term/lifelong suppression of HBV replication without HBV resistance has been well achieved. Unfortunately, the reported rates of $\mathrm{HBsAg}$ loss under treatment have been very low. However, there is rapidly accumulating new evidence demonstrating achievement of sustained remission and HBsAg loss after termination of long term NA therapies, particularly in $\mathrm{HBeAg}$-negative chronic hepatitis $B$ $(\mathrm{CHB})^{8,22-25}$ 
Numerical aspects of chronic HBV infection and its Treatment

Worldwide, there are estimated more than 350 million people chronically infected with HBV. Of them, 2.2 million reside in the USA, 14 million in Europe, and 112 million in the AsianPacific Area. ${ }^{13}$ Although HBV associated liver disease in individuals with chronic active HBV infection often progresses quite slowly over the years; ultimately, mortalities from HBVinduced cirrhosis and HBV-related HCC far exceed those from any other viral and non-viral infection source.

Currently, the rates of HBV endemicity range from $<2 \%$ (low), $2-7 \%$ (intermediate), and $>8 \%$ (high). Of the 300 million people with chronic HBV infection, approximately 600,000 individuals, may die annually from HBV-induced cirrhosis and HCC. ${ }^{12}$

Of the total world pool of chronically HBV infected people, no more than $5 \%$ have been diagnosed and only $1 \%$ to $4 \%$ are actually treated. The rates of diagnosis range from $\leqslant 5 \%$ in Asia and Pacific, $12 \%$ in Europe, and $19 \%$ in USA, and respective treatment rates are $<1 \%, 12 \%$, and $4 \% .{ }^{13}$ The situation does not appear to have improved significantly over the years. In a 2010 report $^{26}$ based on the total number of annual prescriptions for treatment in the USA $(50,000)$, it was calculated that of the 2.2 million with chronic HBV infection only $2.5 \%$ to $5 \%$ receive anti-HBV treatment, even though $20-25 \%$ of individuals are aware of their HBV infection status. Of course, current treatments cannot eradicate or cure $\mathrm{CHB}$, but they can properly suppress the HBV infection to a persistently inactive carrier state and promote HBsAg loss. This outcome is not a cure, however, but it has been referred to as a "functional" cure.

Since numerous studies worldwide have documented that $30 \%$ of patients with chronic HBV infection will develop progressive liver damage terminating in end stage cirrhosis and development of HCC, effective treatment is necessary in at least one third of all hepatitis B patients. ${ }^{12}$ Moreover, HBV infection was shown to be the most frequent etiological factor underlying HCC globally, accounting for approximately $80 \%$ of all cases. In this context, it is notable both from a European and personal point of view, that the link between chronic HBV infection and HCC was first brought to light by Sherlock et al. in 1970 with clinical and epidemiological studies in chronic viral B liver disease in Greece ${ }^{5}$ as well as in Greek and Mediterranean patients from England. ${ }^{4}$ However, up until the early 1970 s, the development of HCC was attributed almost exclusively to aflatoxin exposure, a situation particularly common in Sub-Saharan Africa where HBV endemicity was also high. ${ }^{8}$ It took a number of years and the conduction of wide clinical and epidemiological studies to unequivocally demonstrate and to achieve global acceptance of the connection between chronic HBV infection and HCC. $5,8,9,11$

\section{Previous and current anti-HBV therapeutic strategies}

At first glance, the armamentarium in the treatment of HBV appears to be quite rich, since it contains seven drugs. ${ }^{5}$ However, of the various included drugs, only peg-IFN alpha $2 a$ and the NAs ENT and TDF represent the current first line treatment options. ${ }^{19,20}$ Notably, no new anti-HBV drugs have been approved since 2008. There are several new anti-HBV therapies, however, in different stages of preclinical and clinical development. They include: a) novel anti-HBV NAs that are phosphonates similar to ADV and TDF and TDF derivatives with improved pharmacological properties, all now in advanced stages of clinical development; b) antisense DNA molecules; c) insertional RNA molecules; d) inhibitors of HBV uptake by hepatocytes; e) capsid formation inhibitors; f) RNase H blockers; and g) blockers of histone modification. ${ }^{27-31}$ These agents act at various stages of the HBV life cycle, including uptake and entry in hepatocytes, numerous points of its replication process, and secretion of new hepatitis $B$ virions into the circulation. ${ }^{12}$ Since these compounds remain under investigation, they will not be further discussed in this review. ${ }^{15,27-31}$

\section{Aims and goals of treatment in CHB}

Despite significant progress over the years regarding all aspects of HBV infection, particularly its prevention and treatment, $\mathrm{CHB}$ remains a strictly non-curable infection because residual cccDNA of the virus can always be detected in the liver, even after clearance of serum HBsAg and the development of anti-HBs. ${ }^{18}$ Moreover, HBV DNA sequences integrate into the genome of hepatocytes, as demonstrated in HBsAg negative individuals in the early 1980 s. $^{32}$ Therefore, it follows that the term "cure" cannot be applied for a disease that cannot be completely eradicated. The achievement of HBsAg loss, which is generally viewed as the closest outcome to a cure, is widely referred to as a functional cure. Its achievement represents a major goal of current treatment efforts in CHB.

The incidence of HBsAg loss during and after stopping anti-HBV treatment depends on various factors. These include the appropriate selection of administered drugs, characteristics of patients, duration of treatment, handling and monitoring of therapy, and application of relevant markers as determinants and predictors of sustained responses after discontinuation of therapy.

Early on during the development of anti-HBV therapies, the aim of successful treatment was to achieve a number of endpoints, hoping at the same time, that such endpoints will be sustained after discontinuation of therapy. Since HBsAg loss was rarely, if ever, achievable by finite courses of therapy, this outcome was not one of the endpoints of therapy. Serological, virological, and even histological endpoints have been evaluated as surrogate markers of favorable long term outcome of chronic HBV infection, without development of cirrhosis and of HCC. However, none of these endpoints turned out to be a reliable surrogate marker of favorable long term outcome of $\mathrm{CHB}$. Thus, for the time being, HBsAg loss is viewed and applied as the best possible predictor of a favorable long term outcome of the infection. ${ }^{23,24}$ Nevertheless, it should be noted that HBsAg loss is not synonymous with regression of the underlying liver histology to normal or with prevention of HCC.

Initiation of therapy in $\mathrm{CHB}$ is recommended by AASLD, EASL, and APASL on the basis of quite similar, but not identical, criteria of HBV DNA and alanine aminotransferase (ALT) activity. ${ }^{19-21}$

When deciding on the appropriate treatment, several factors should be considered. These are related to:

1. Patients' characteristics: age, contraindications, previous treatment, co-morbidities, co-infections, genetics, personal needs, and compliance.

2. Features of HBV infection: HBeAg status, HBV DNA levels, HBV genotypes, and viral heterogeneity. 
3. Liver disease parameters: ALT levels, grade of necroinflammation, and stage of fibrosis.

4. Drug properties and characteristics: efficacy, side effects, and HBV resistance profile, including availability and cost. ${ }^{33}$

Attempts to optimize the cost/effectiveness of IFN-based therapies, including combined treatment of NAs and IFN, longer duration of therapy, and identification of pre-and ontreatment predictors of response, are also important. ${ }^{12,33,34}$

Current anti-HBV therapies will be reviewed under the following three headings:

A. Treatment with courses of IFN-alpha.

B. Finite and indefinite treatment with NAs, including the emerging new treatment paradigm of discontinuing long term NA therapy in HBeAg negative CHB patients. ${ }^{23}$

C. Treatment with NAs combined with courses of IFN-alpha.

\section{A) Treatment with IFN alpha}

The recombinant form of IFN alpha2b was the first drug registered for the treatment of $\mathrm{CHB}^{5}$ Its therapeutic efficacy was first evaluated in the 1980s in patients with HBeAgpositive $\mathrm{CHB}$, when the existence of $\mathrm{HBeAg}$-negative $\mathrm{CHB}$ had not yet been recognized internationally. HBe-Ag-negative $\mathrm{CHB}$, which currently represents the most frequent form of active viral B liver disease, was viewed initially with skepticism. ${ }^{5,8} \mathrm{HBeAg}$-negative $\mathrm{CHB}$ was considered refractory to IFN treatment because of high rates of relapse after discontinuation of therapy with conventional IFN alpha. 8,35 Thus, there were no international trials of conventional IFN alpha (either $2 \mathrm{a}$ or $2 \mathrm{~b}$ ) conducted in HBeAg-negative CHB. However, the efficacy of treatment and re-treatment with conventional IFN alpha, lasting for one and even two years, has been well documented in the Mediterranean Area. ${ }^{5}$ In a single center study from Greece, sustained off treatment responses, including HBsAg loss, were achieved by treatment and re-treatment in approximately $20 \%$ of patients; while $40 \%$ of sustained responders achieved HBsAg loss at year five of follow-up. ${ }^{36}$ Similar results were obtained in the first international multicenter 2 year trial of peg-IFN 2a in HBeAgnegative $\mathrm{CHB} .{ }^{37}$ The post-treatment follow-up of this study was extended to 5 years in a majority of the patients and has provided additional evidence on the long term efficacy of this treatment in $\mathrm{HBeAg}$-negative $\mathrm{CHB}$. The results have been reported widely in the world literature and numerous publications have replicated this finding. ${ }^{38,39}$

The use of peg-IFN alpha2a for 2 years has also been evaluated in the treatment of $\mathrm{HBeAg}$-positive $\mathrm{CHB}^{40}$ The efficacy of peg-IFN alpha 2a was compared with both the NA lamivudine (3TC) and the combination Peg-IFN and 3TC. In terms of sustained post-treatment response, treatment with peg-IFN alpha 2a was superior to 3TC monotherapy and not different from the combination group. These findings signaled the comeback of IFN as a first line therapeutic for both $\mathrm{HBeAg}$-negative and positive $\mathrm{CHB}$.

An advantage of alpha IFNs over NAs is the absence of the development of HBV resistance. Because of their immunological mode of action, IFNs can induce sustained posttreatment control of $\mathrm{CHB}$, terminating in $\mathrm{HBsAg}$ loss in $20-30 \%$ of all treated patients. ${ }^{15,34,41,42}$ With appropriate selection of patients, this percentage can be increased to $40 \% .{ }^{43}$ However, IFN-alpha has several contraindications and side effects; and even in properly selected patients, it is important to monitor therapy by appropriate predictors of response. By monitoring this mode of treatment with pre and on-therapy measurements of serum HBV DNA levels and HBsAg titers, it is possible to predict with significant accuracy the possibility of sustained response rates. ${ }^{33,44}$ Moreover, for $\mathrm{HBeAg}$-negative $\mathrm{CHB}$, if high serum HBV DNA and $\mathrm{HBsAg}$ levels persist during early IFN treatment, it is unlikely that this treatment will be efficacious. Based on these findings, if $\mathrm{CHB}$ is unresponsive to IFN, treatment should be stopped in order to avoid the numerous possible side effects.

Regarding clinically applicable variables for predicting sustained response, genetic polymorphisms of several residues upstream of the IL28B (currently the IFN $\lambda 3$ ) gene has been evaluated in both Western and Asiatic studies in patients infected with various HBV genotypes. ${ }^{45}$ Predictors of response to treatment represent a clinically important topic and polymorphisms in the HLA response genes and others alone or in combination are currently under investigation.

Combination therapy using conventional or peg-IFN-alpha and several NAs have been reported, with the rationale that combining the strong antiviral activity of NAs with anti-viral and immunomodulatory activities of IFN-alpha would have a synergistic anti CHB effect. The efficacy of such combination therapies and the addition of IFN-alpha to long term NA therapy in $\mathrm{HBeAg}$-negative $\mathrm{CHB}$ will be reviewed in section $\mathrm{C}$.

\section{B) Treatment with Nucleos(t)ide Analogues}

The first NA used for the treatment of CHB was 3TC, an inhibitor of reverse transcriptase that transcribes the RNA of human immunodeficiency virus (HIV) to DNA. Three TC inhibits HBV replication by blocking an obligatory step in the $\mathrm{HBV}$ cycle of replication, reverse transcription of pregenomic RNA to genomic HBV DNA. ${ }^{9,14,46}$ The use of 3TC has revolutionized the management of all stages of $\mathrm{CHB}$, from its early histological phases to the advanced stages of fibrosis, even in decompensated cirrhosis and in the setting of liver transplantation. ${ }^{8,12,15}$ Now, more than 15 years after the introduction of 3TC for the treatment of CHB, we are privileged to continue to apply very long term and even lifelong potent NA therapies with high barrier to HBV resistance. Not only can maintenance of virological and biochemical remission with impressive improvement of liver necroinflammation be achieved but also high rates of regression of hepatic fibrosis and even reversion of cirrhosis. ${ }^{47,48}$

Of the five hitherto approved anti-HBV NAs, ENT and TDF act not only in the inhibition of reverse transcription but also in the inhibition of protein priming. ${ }^{49}$ After the entry of hepatitis $B$ virions in hepatocytes and the cytosolic transport of core particles to the nucleus, cccDNA is formed. Similar to host chromosomes, the cccDNA of HBV complexes with cellular histone and non-histone proteins. ${ }^{46}$ This is followed by replication of HBV via transcription and translation of the viral genes and encapsidation of pregenomic HBV RNA. By reverse transcription, genomic HBV DNA is generated and $H B$ virions are released by budding and secretion. ${ }^{49}$ Protein binding is important step in the process of reverse transcription, and its inhibition by NAs constitutes an additional target of therapy.

It has been estimated that the 5 year rate of development of HBV resistance is around $70 \%$ for 3TC, $29 \%$ for Adefovir (ADV), and $34 \%$ for TDF at 3 years. ${ }^{13,49,50}$ Long term clinical studies of ENT and TDF monotherapy have demonstrated that 
the risk for HBV resistance is very low, at $1.2 \%$ after 6 years of therapy for ENT and even more rare for TDF after $>5$ years of therapy. Although virological breakthroughs have been observed occasionally with these drugs, there were no demonstrable resistance mutations. ${ }^{13,49,50}$

The major mutational patterns conferring resistance to NAs are the combination of rtL180M/rt M204I/V for 3TC and rt A181V/rtN236T for ADV or TDF. Although viral resistance is very low for ENT and TDF, novel NAs derivatives with improved pharmacological properties, including phosphonates similar to ADV and TDF, are being evaluated currently in advanced clinical trials.

Treatment of CHB in clinical practice with NAs is either applied a) in finite courses, usually of one or two years duration or b) indefinitely/lifelong. ${ }^{15,33,34,50}$

a) Finite courses of NA therapy have been tried in all $\mathrm{CHB}$ patients. HBeAg-negative patients fail to achieve sustained responses and exhibit extremely high rates of relapse after termination of therapy. ${ }^{22,50}$ Thus, finite courses have been restricted to the subset of $\mathrm{HBeAg}$ positive patients, often with a rather limited percentage of sustained response. ${ }^{15,33,34}$ Moreover, even in those HBeAg-positive patients who may achieve HBeAg-seroconversion under finite courses of NA treatment, a quite long consolidation period is necessary. Therefore, finite courses of IFN treatment in $\mathrm{HBeAg}$-positive patients are preferable to NA therapy, provided, of course, that the side effects of IFN are tolerable and the application of the drug is not contraindicated for any reason, such as advanced cirrhosis or autoimmune disease.

b) In the current AASLD and EASL Treatment Guidelines for HBeAg-negative patients, long term/indefinite NA therapy is recommended, whereas the APASL Treatment Guidelines recommend its discontinuation if serum HBV
DNA becomes undetectable in three consecutive assays 6 months apart. ${ }^{19-21}$ With the current first line NAs (ENT and TDF) with high potency and high barrier to HBV resistance, biochemical and virological remission can be achieved in practically all treated patients. Thus, in a real life setting it represents the current treatment of choice not only for the vast majority of HBAg-negative patients, but also for those HBeAg-positive ones that are nonresponsive to or ineligible for IFN treatment. $5,29,33,50$ Long term NA therapy with ENT or TDF is also the treatment of choice for all HBV patients with cirrhosis, regardless of $\mathrm{HBeAg}$ status. ${ }^{19,20}$

The main problem with long term NA therapy in HBeAgnegative $\mathrm{CHB}$ is the very low frequency of HBsAg loss, limited to only $1-2 \%$ per year. ${ }^{51}$ Moreover, based on declining HBsAg titers under treatment, it has been estimated that loss of HBsAg may take several decades to occur. On the other hand, if effective long term NA therapy in $\mathrm{HBeAg}$-negative $\mathrm{CHB}$ is discontinued, then a post-treatment immunological control of the disease terminating in HBsAg loss can be encountered. ${ }^{23}$ Such an outcome has been reported recently in a number of retrospective and prospective studies (see review). ${ }^{22}$

In $\mathrm{HBeAg}$-negative $\mathrm{CHB}$, sustained responses after stopping long term NA therapy followed by HBsAg loss become highly probable if $\mathrm{HBsAg}$ titers were already significantly reduced with treatment to levels $<500 \mathrm{IU} / \mathrm{mL}$, preferably $<100$ units. ${ }^{51,52}$ The possible mechanism(s) by which such a favorable outcome is induced is under study but all hitherto available evidence supports an immunologically induced mechanism. ${ }^{18,22,53}$ Interestingly, post-treatment ALT flares exhibit similar features of immunologically induced ones. First, HBV replication resumes, HBV DNA reappears in serum, ALT levels increase, and serum levels of IFN- $\gamma$-Inducible Protein 10 (IP-10) and anti-HBc IgM increase (Fig. 1).

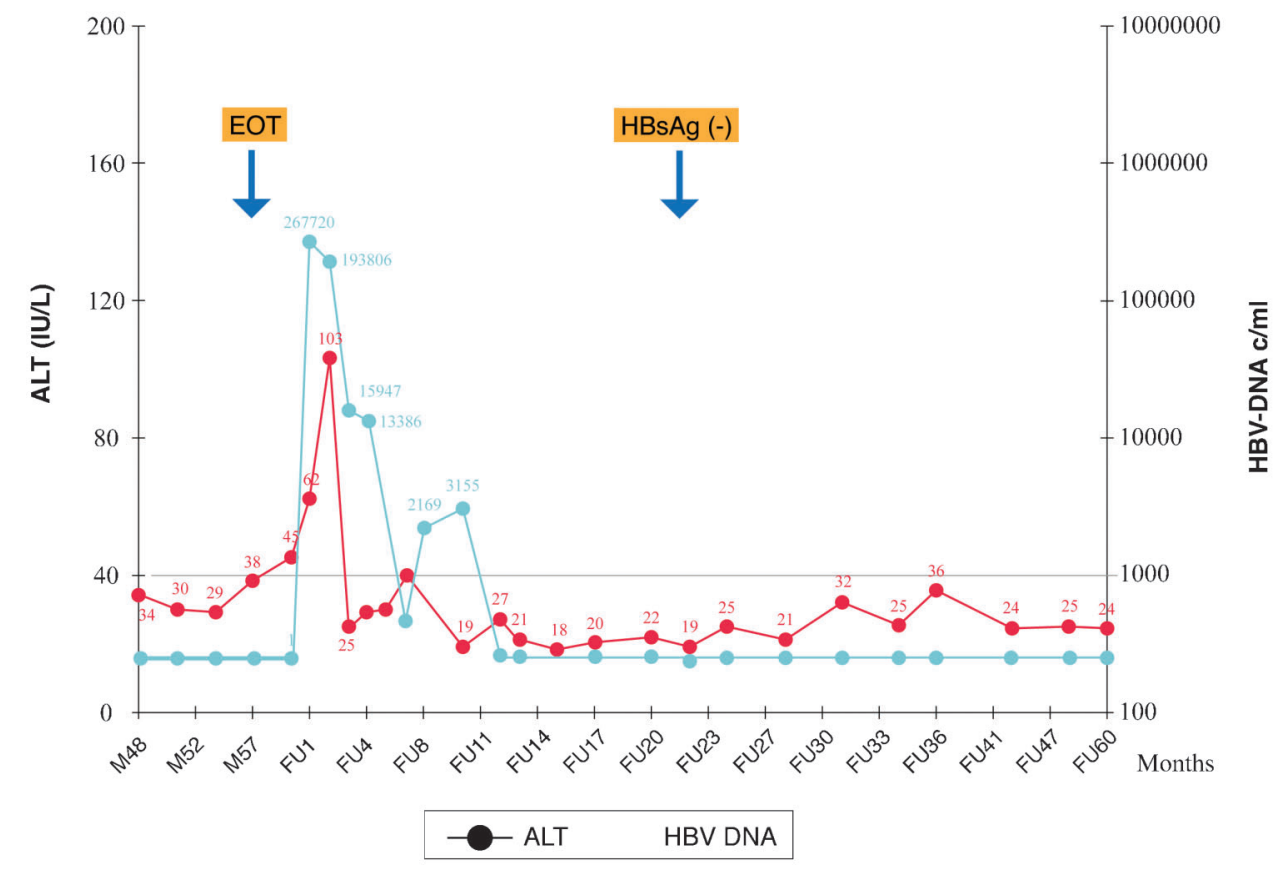

Fig. 1. Withdrawal of ADV treatment after 5 years in an HBeAg negative patient with CHB (first arrow in the left) followed by virological relapse and subsequent increase in ALT (clinical relapse). The patient was no retreated and was monitored at 2 week intervals. Note the delay in spontaneous resolution of the relapse and that HBsAg was cleared later. HBV DNA was measured in copies/mL (From: Hadziyannis et al., 2014). ${ }^{22,23}$ 
Notably, in patients with a major decrease in the number of $\mathrm{HBsAg}$ positive hepatocytes on liver biopsy and with a major reduction of cccDNA in the liver already at the end of long term NA treatment (personal unpublished data) such an immune-mediated anti-HBV effect appears to be sufficient to clear any residual HBV and HBsAg-positive hepatocytes. Recent immunological studies also suggest that while high HBsAg levels suppress the host immune reactivity against $\mathrm{HBV}$, significant reduction of HBsAg levels with NA therapy may lead to restoration of immune anti-HBV activity. ${ }^{18,53,54}$

Regardless of the mechanism(s) of induction of $\mathrm{HBsAg}$ clearance after discontinuation of long term NA treatment in $\mathrm{CHB}$, such a therapeutic approach clearly represents a new treatment paradigm, at least for $\mathrm{HBeAg}$-negative patients. This, however, is recommended only by the APASL Guidelines. ${ }^{21}$ The main objection to this approach is the possibility of clinical relapse after stopping long term NA therapy and the danger to patients with already developed cirrhosis. ${ }^{55}$ However published guidelines for safe discontinuation of long term NA therapy recommend, among else, stringent post-treatment monitoring and retreatment only in case of persisting clinical relapse, an approach also followed in most hitherto studies. ${ }^{23,25,56}$ Discontinuation of long term NA treatment in HBeAg-negative $\mathrm{CHB}$ revealed maintenance of high responses rates off treatment in seven out of the ten studies, ranging from $43 \%$ to $70 \%$, and a high safety profile under appropriate monitoring. ${ }^{22}$ Certainly, there are clinical concerns and objections for discontinuation of NA therapy in patients with advanced stages of liver disease. However, according to Asiatic studies, discontinuation of long term NA therapy can be safe, even in patients with cirrhosis. ${ }^{57,58}$ In addition, it is important to emphasize that early post-treatment increases in serum HBV DNA followed by flares of ALT activity are usually short-lived and should be first monitored for spontaneous resolution rather than being immediately retreated. ${ }^{23}$

Based on the study of $\mathrm{HBsAg}$ titers with long term NA treatment of $\mathrm{HBeAg}$-negative $\mathrm{CHB}$, it appears that upon termination of therapy, sustained virological responses, and $\mathrm{HBsAg}$ loss are highly probable if HBsAg titers were already significantly reduced during treatment (to levels $<500 \mathrm{IU} /$ $\mathrm{mL}$, preferably $<100$ units) (Fig. 2). In this context, the

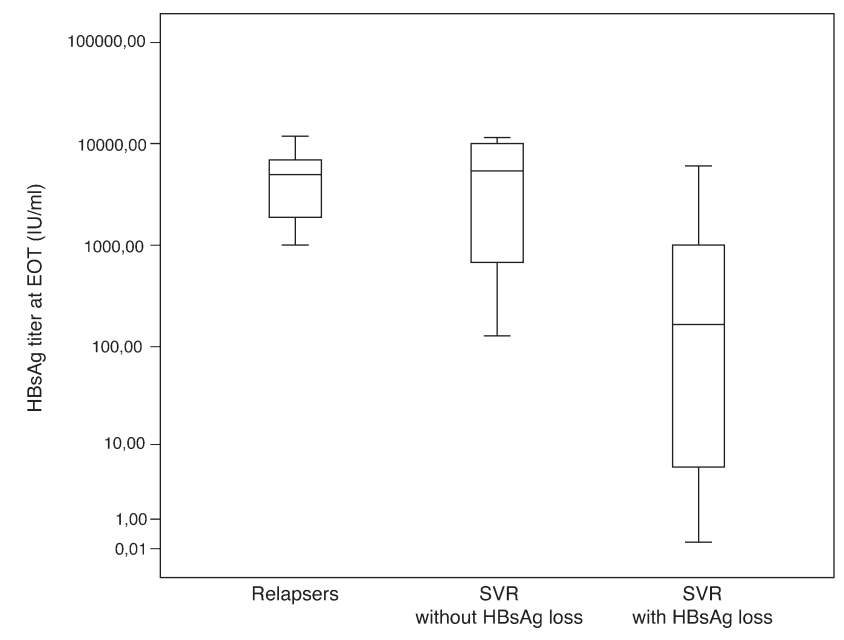

Fig. 2. Low levels of HBsAg at the end of long term treatment (EOT) with NAs are associated with sustained off-treatment response and HBsAg
loss. ${ }^{22,23}$ addition of a course of Peg-IFN to ongoing NA therapy may be helpful. ${ }^{59}$

\section{C) Combination NA and IFN therapy}

The efficacy achieved by NAs alone or in combination with IFN for the treatment of CHB has been compared by several schemes of combination therapy. The current state of the art on such combination therapies and on the addition of IFN to short and long-term NA therapy regimens has been reviewed by several authors. ${ }^{18,33,43,50,53,60,61}$

The results from studies comparing the efficacy of various combinations of IFN-alpha and NAs versus IFN and NAs alone have been rather controversial. ${ }^{60}$ According to trials, there was no difference in efficacy between combination therapy of peg-IFN and NAs and either peg-IFN or NA alone. However, combination therapy was associated with reduced levels of $\mathrm{HBV}$ resistance relative to $3 \mathrm{TC}$ alone. A recent meta-analysis demonstrated that combination therapy is superior in terms of end of treatment results but not regarding sustained off treatment responses. ${ }^{61}$

Because of low rates of HBsAg loss under NA therapy and the low rates of sustained responses after stopping finite courses of NA treatment, clinical investigators have been motivated to add courses of pegIFN alpha 2 a of variable duration to ongoing NA treatment. ${ }^{59,62,63}$ This type of combination treatment aims to promote HBsAg loss either under therapy or after its discontinuation, and it represents an immunologically sound approach. To date, the results are quite promising. ${ }^{18,53}$

\section{Conclusions}

$\mathrm{CHB}$ is an important public health problem that, despite the achievement of significant progress in all aspects over the years, continues to be under-diagnosed and undertreated worldwide. With the use of current first line NAs, the replication of HBV can be suppressed in practically all patients to non-detectable serum HBV DNA levels with negligible, if any, development of HBV resistant mutants. Long lasting suppression of HBV replication can lead to histological improvement, reversal of advanced stages of fibrosis, reduction in the rates of progression of $\mathrm{CHB}$ to cirrhosis and its complications, and even reduction, but not elimination, of the risk for HCC development. Long term NA therapy, especially with ENT and TDF, is currently administered to the majority of $\mathrm{CHB}$ patients. Unfortunately, the rate of HBsAg loss, the closest to cure outcome of chronic HBV infection, is rare and restricted to only $1-2 \%$ per year. Thus, for such a favorable outcome to occur, NA therapy must continue for several decades or for life. This is not always feasible, given potential issues with cost, availability, compliance, and onset of unforeseeable side effects. It should be kept in mind, however that prior to the administration of long term NA therapy both in $\mathrm{HBeAg}$-positive and $\mathrm{HBeAg}$-negative patients with $\mathrm{CHB}$, a course of IFN alpha treatment is of order unless patients are not eligible or IFN treatment is contraindicated. It should be also emphasized that if $\mathrm{HBeAg}$ seroconversion is achieved in the treatment of HBeAg-positive patients with NAs, then a long consolidation period should be implemented.

Currently, the topic of discontinuing long term NA therapy in patients under virological and biochemical remission is 
being investigated clinically, particularly in HBeAg-negative $\mathrm{CHB}$. It is safe and can be followed by sustained long term clinical remission and subsequent HBsAg loss and development of anti-HBs. Such treatment-related outcomes appear to be immunologically mediated and can be achieved at rates even higher than $50 \%$.

The goal of courses of treatment with IFN alpha (up to 2 years) is the achievement of sustained virological remission and subsequent HBsAg loss. In properly selected patients, courses of IFN can be added to ongoing NA treatment. The rate of sustained responses is approximately $20 \%$, but this can be increased in both $\mathrm{HBeAg}$-positive and $\mathrm{HBeAg}$-negative $\mathrm{CHB}$ patient by the application of a stopping rule based on non-decline in HBsAg and HBV DNA levels early under treatment.

Although the risk for HCC development is reduced when HBsAg loss is achieved therapeutically, its development is still, unfortunately, possible. Currently, novel therapies with various anti-HBV compounds are in development and their use clinically may prove to be successful at achieving the closest to cure outcome of HBsAg loss.

\section{Conflict of interest}

None

\section{Author contributions}

Writing the review $(\mathrm{SJH})$.

\section{References}

[1] Blumberg BS, ALTER HJ, VISNICH S. A "new" antigen in leukemia sera. JAMA 1965;191:541-546. doi: 10.1001/jama.1965.03080070025007.

[2] London WT, Sutnick AI, Blumberg BS. Australia antigen and acute viral hepatitis. Ann Intern Med 1969;70:55-59. doi: 10.7326/0003-4819-70-1-55.

[3] Dane DS, Cameron CH, Briggs M. Virus-like particles in serum of patients with Australia-antigen-associated hepatitis. Lancet 1970;1:695-698. doi: 10.1016/S0140-6736(70)90926-8.

[4] Sherlock S, Fox RA, Niazi SP, Scheuer PJ. Chronic liver disease and primary liver-cell cancer with hepatitis-associated (Australia) antigen in serum. Lancet 1970;1:1243-1247. doi: 10.1016/S0140-6736(70)91737-X.

[5] Hadziyannis SJ. Milestones and perspectives in viral hepatitis B. Liver Int 2011;31(Suppl 1):129-134. doi: 10.1111/j.1478-3231.2010.02406.x.

[6] Trepo C. A brief history of hepatitis milestones. Liver Int 2014;34(Suppl 1):2937. doi: 10.1111/liv.12409.

[7] Thomas HC. The hepatitis B virus and the host response. J Hepatol 1990; 11(Suppl 1):S83-S89.

[8] Lok AS. Progress in hepatitis B: a 30-year journey through three continents. Hepatology 2014;60:4-11. doi: 10.1002/hep.27120.

[9] Ganem D, Prince AM. Hepatitis B virus infection-natural history and clinical consequences. N Engl J Med 2004;350:1118-1129. doi: 10.1056/ NEJMra031087.

[10] Grimm D, Heeg M, Thimme R. Hepatitis B virus: from immunobiology to immunotherapy. Clin Sci (Lond) 2013;124:77-85. doi: 10.1042/ CS20120169.

[11] Trepo C, Chan HL, Lok A. Hepatitis B virus infection. Lancet 2014 June 18. doi: 10.1016/S0140-6736(14)60220-8.

[12] Hadziyannis SJ, Vassilopoulos D, Hadziyannis E. The natural course of chronic hepatitis B virus infection and its management. Adv Pharmacol 2013; 67:247-291. doi: 10.1016/B978-0-12-405880-4.00007-X.

[13] Kuo A, Gish R. Chronic hepatitis B infection. Clin Liver Dis 2012;16:347-369. doi: $10.1016 /$ j.cld.2012.03.003.

[14] Lee WM. Hepatitis B virus infection. N Engl J Med 1997;337:1733-1745. doi: 10.1056/NEJM199712113372406

[15] Liaw YF. Impact of therapy on the long-term outcome of chronic hepatitis B. Clin Liver Dis 2013;17:413-423. doi: 10.1016/j.cld.2013.05.005.

[16] van BF, Berg T. Antiviral therapy of chronic hepatitis B. Intervirology 2014; 57:171-180. doi: 10.1159/000360945.
[17] Deny P, Zoulim F. Hepatitis B virus: from diagnosis to treatment. Pathol Biol (Paris) 2010;58:245-253. doi: 10.1016/j.patbio.2010.05.002.

[18] Rehermann B, Bertoletti A. Immunological aspects of antiviral therapy of chronic hepatitis B virus and hepatitis C virus infections. Hepatology 2014 July 21. doi: 10.1002/hep.27323.

[19] Lok AS, McMahon B]. Chronic hepatitis B: update 2009. Hepatology 2009; 50:661-662. doi: 10.1002/hep.23190.

[20] European Association For The Study Of The Liver. EASL clinical practice guidelines: Management of chronic hepatitis B virus infection. J Hepatol 2012;57:167-185. doi: 10.1016/j.jhep.2012.02.010.

[21] Liaw YF, Kao JH, Piratvisuth T, Chan HLY, Chien RN, Liu CJ, et al. Asian-Pacific consensus statement on the management of chronic hepatitis B: a 2012 update. Hepatol Int 2012;6:531-561. doi: 10.1007/s12072-012-9365-4.

[22] Hadziyannis SJ, Vassilopoulos D, Hadziyannis E. Can Nucleos(t)ide Analogue (NA) Therapy Ever be Stopped in HBeAg-Negative Chronic Hepatitis B? Curr Hepatol Rep 2014;13:256-263. doi: 10.1007/s11901-014-0236-4.

[23] Hadziyannis SJ, Sevastianos V, Rapti I, Vassilopoulos D, Hadziyannis E. Sustained responses and loss of HBsAg in HBeAg-negative patients with chronic hepatitis B who stop long-term treatment with adefovir. Gastroenterology 2012:143:629-636. doi: 10.1053/j.gastro.2012.05.039.

[24] Hadziyannis E, Hadziyannis SJ. Hepatitis B surface antigen quantification in chronic hepatitis B and its clinical utility. Expert Rev Gastroenterol Hepatol 2014;8:185-195. doi: 10.1586/17474124.2014.876362.

[25] Patwardhan VR, Sengupta N, Bonder A, Lau D, Afdhal NH. Treatment cessation in noncirrhotic, e-antigen negative chronic hepatitis $B$ is safe and effective following prolonged anti-viral suppression with nucleosides/nucleotides. Aliment Pharmacol Ther 2014;40:804-810. doi: 10.1111/apt.12908.

[26] Cohen C, Holmberg SD, McMahon BJ, Block JM, Brosgart CL, Gish RG, et al. Is chronic hepatitis $B$ being undertreated in the United States? J Viral Hepat 2011;18:377-383. doi: 10.1111/j.1365-2893.2010.01401.x.

[27] Fletcher SP, Delaney WE. New therapeutic targets and drugs for the treatment of chronic hepatitis B. Semin Liver Dis 2013;33:130-137. doi: 10.1055/s-0033-1345713.

[28] Wang $X Y$, Chen HS. Emerging antivirals for the treatment of hepatitis $B$. World J Gastroenterol 2014;20:7707-7717. doi: 10.3748/wjg.v20. i24.7707.

[29] Tang CM, Yau TO, Yu J. Management of chronic hepatitis B infection: current treatment guidelines, challenges, and new developments. World J Gastroenterol 2014;20:6262-6278. doi: 10.3748/wjg.v20.i20. 6262.

[30] Qiu LP, Chen L, Chen KP. Antihepatitis B therapy: a review of current medications and novel small molecule inhibitors. Fundam Clin Pharmaco 2014;28:364-381. doi: 10.1111/fcp.12053.

[31] Glebe D, Konig A. Molecular virology of hepatitis B virus and targets for antiviral intervention. Intervirology 2014;57:134-140. doi: 10.1159/ 000360946.

[32] Shafritz DA, Shouval D, Sherman HI, Hadziyannis SJ, Kew MC. Integration of hepatitis B virus DNA into the genome of liver cells in chronic liver disease and hepatocellular carcinoma. Studies in percutaneous liver biopsies and post-mortem tissue specimens. N Engl J Med 1981;305:1067-1073. doi: 10.1056/NEJM198110293051807.

[33] Santantonio TA, Fasano M. Chronic hepatitis B: Advances in treatment. World J Hepatol 2014;6:284-292. doi: 10.4254/wjh.v6.i5.284.

[34] Yuen MF, Lai CL. Treatment of chronic hepatitis B: Evolution over two decades. J Gastroenterol Hepatol 2011;26(Suppl 1):138-143. doi: 10.1111/ j.1440-1746.2010.06545.x.

[35] Hadziyannis SJ, Vassilopoulos D. Hepatitis B e antigen-negative chronic hepatitis B. Hepatology 2001;34:617-624. doi: 10.1053/jhep.2001.27834

[36] Manesis EK, Hadziyannis SJ. Interferon alpha treatment and retreatment of hepatitis B e antigen-negative chronic hepatitis B. Gastroenterology 2001; 121:101-109. doi: 10.1053/gast.2001.25524.

[37] Marcellin $\mathrm{P}$, Lau GK, Bonino $F$, Farci $\mathrm{P}$, Hadziyannis $\mathrm{S}$, Jin $\mathrm{R}$, et al. Peginterferon alfa-2a alone, lamivudine alone, and the two in combination in patients with HBeAg-negative chronic hepatitis B. N Engl J Med 2004;351: 1206-1217. doi: 10.1056/NEJMoa040431.

[38] Marcellin P, Bonino F, Yurdaydin C, Hadziyannis S, Moucari R, Kapprell HP, et al. Hepatitis B surface antigen levels: association with 5 -year response to peginterferon alfa-2a in hepatitis $B$ e-antigen-negative patients. Hepatol Int 2013;7:88-97. doi: 10.1007/s12072-012-9343-X.

[39] Brunetto MR, Marcellin P, Cherubini B, Yurdaydin C, Farci P, Hadziyannis SJ, et al. Response to peginterferon alfa-2a (4OKD) in HBeAg-negative CHB: ontreatment kinetics of HBsAg serum levels vary by HBV genotype. J Hepato 2013:59:1153-1159. doi: 10.1016/j.jhep.2013.07.017.

[40] Lau GK, Piratvisuth T, Luo KX, Marcellin P, Thongsawat S, Cooksley G, et al. Peginterferon Alfa-2a, lamivudine, and the combination for HBeAg-positive chronic hepatitis B. N Engl J Med 2005;352:2682-2695. doi: 10.1056/ NEJMoa043470.

[41] Dusheiko G. Treatment of HBeAg positive chronic hepatitis B: interferon or nucleoside analogues. Liver Int 2013;33(Suppl 1):137-150. doi: 10.1111/ liv. 12078. 
[42] Vigano M, Mangia G, Lampertico P. Results of treatment of chronic hepatitis B with pegylated interferon. Clin Liver Dis 2013;17:425-443. doi: 10.1016/ j.cld.2013.05.004

[43] Lampertico P, Liaw YF. New perspectives in the therapy of chronic hepatitis $B$. Gut 2012;61 (Suppl 1):i18-i24. doi: 10.1136/gutjnl-2012-302085.

[44] Hadziyannis E, Hadziyannis SJ. Hepatitis B surface antigen quantification in chronic hepatitis B and its clinical utility. Expert Rev Gastroenterol Hepatol 2014;8:185-195. doi: 10.1586/17474124.2014.876362.

[45] Galmozzi E, Vigano M, Lampertico P. Systematic review with meta-analysis: do interferon lambda 3 polymorphisms predict the outcome of interferontherapy in hepatitis B infection? Aliment Pharmacol Ther 2014;39:569-578. doi: 10.1111/apt.12631.

[46] Levrero M, Pollicino T, Petersen J, Belloni L, Raimondo G, Dandri M. Control of cccDNA function in hepatitis B virus infection. J Hepatol 2009;51:581-592. doi: $10.1016 /$ j.jhep.2009.05.022.

[47] Marcellin P, Gane E, Buti M, Afdhal N, Sievert W, Jacobson IM, et al. Regression of cirrhosis during treatment with tenofovir disoproxil fumarate for chronic hepatitis B: a 5-year open-label follow-up study. Lancet 2013; 381:468-475. doi: 10.1016/S0140-6736(12)61425-1.

[48] Chang TT, Liaw YF, Wu SS, Schiff E, Han KH, Lai CL, et al. Long-term entecavir therapy results in the reversal of fibrosis/cirrhosis and continued histological improvement in patients with chronic hepatitis B. Hepatology 2010;52:886893. doi: 10.1002/hep.23785.

[49] Menendez-Arias L, Alvarez M, Pacheco B. Nucleoside/nucleotide analog inhibitors of hepatitis $B$ virus polymerase: mechanism of action and resistance. Curr Opin Virol 2014;8C:1-9. doi: 10.1016/j.coviro.2014.04.005.

[50] Tujios SR, Lee WM. Update in the management of chronic hepatitis B. Curr Opin Gastroenterol 2013;29:250-256. doi: 10.1097/MOG.0b013e32835ff1e9.

[51] Chen CH, Chiu YC, Lu SN, Lee CM, Wang JH, Hu TH, et al. Serum hepatitis B surface antigen levels predict treatment response to nucleos(t)ide analogues. World J Gastroenterol 2014;20:7686-7695. doi: 10.3748/wjg.v20.i24.7686.

[52] Chen $\mathrm{CH}$, Lu SN, Hung $\mathrm{CH}$, Wang JH, Hu TH, Changchien CS, et al. The role of hepatitis B surface antigen quantification in predicting HBsAg loss and HBV relapse after discontinuation of lamivudine treatment. J Hepatol 2014;61: 515-522. doi: 10.1016/j.jhep.2014.04.029.

[53] Bertoletti A, Gehring AJ. Immune therapeutic strategies in chronic hepatitis B virus infection: virus or inflammation control? PLoS Pathog 2013;9: e1003784. doi: 10.1371/journal.ppat.1003784
[54] Boni C, Laccabue D, Lampertico P, Giuberti T, Vigano M, Schivazappa S, et al. Restored function of HBV-specific T cells after long-term effective therapy with nucleos(t)ide analogues. Gastroenterology 2012;143:963-973. doi: 10.1053/j.gastro.2012.07.014.

[55] Reijnders JG, Janssen HL. Relapse of chronic hepatitis B after discontinuation of nucleos(t)ide analogs: is the glass half full or half empty? Hepatology 2013; 58:1885-1887. doi: 10.1002/hep.26708.

[56] Tanaka E, Matsumoto A. Guidelines for avoiding risks resulting from discontinuation of nucleoside/nucleotide analogs in patients with chronic hepatitis B. Hepatol Res 2014;44:1-8. doi: 10.1111/hepr.12108.

[57] He D, Guo S, Chen W, Chen X, Yan G, Wang J, et al. Long-term outcomes after nucleos(t)ide analogues discontinuation in chronic hepatitis $B$ patients with HBeAg-negative. BMC Infect Dis 2013;13:458. doi: 10.1186/1471-2334$13-458$.

[58] Jeng W], Sheen IS, Chen YC, Hsu CW, Chien RN, Chu CM, et al. Off-therapy durability of response to entecavir therapy in hepatitis $B$ e antigen-negative chronic hepatitis B patients. Hepatology 2013;58:1888-1896. doi: 10.1002/ hep.26549.

[59] Ouzan D, Penaranda G, Joly H, Khiri H, Pironti A, Halfon P. Add-on peginterferon leads to loss of HBsAg in patients with $\mathrm{HBeAg}$-negative chronic hepatitis and HBV DNA fully suppressed by long-term nucleotide analogs. J Clin Virol 2013;58:713-717. doi: 10.1016/j.jcv.2013.09.020.

[60] Manesis EK, Papatheodoridis GV, Hadziyannis SJ. A partially overlapping treatment course with lamivudine and interferon in hepatitis $B$ e antigennegative chronic hepatitis B. Aliment Pharmacol Ther 2006;23:99-106. doi: 10.1111/j.1365-2036.2006.02731.x.

[61] Li MY, Yuan XL, Zhang DZ. Comparison of peg-interferon monotherapy to peg-interferon and nucleoside analogue combination therapy for hepatitis $B$ : a meta-analysis of randomized controlled trials. Zhonghua Gan Zang Bing Za Zhi 2012;20:442-447. doi: 10.3760/cma.j.issn.1007-3418.2012.06.013.

[62] Barone M, Iannone A, Di Leo A. HBsAg clearance by Peg-interferon addition to a long-term nucleos(t)ide analogue therapy. World J Gastroenterol 2014 20:8722-8725. doi: 10.3748/wjg.v20.i26.8722.

[63] Kittner JM, Sprinzl MF, Grambihler A, Weinmann A, Schattenberg JM, Galle $\mathrm{PR}$, et al. Adding pegylated interferon to a current nucleos(t)ide therapy leads to $\mathrm{HBsAg}$ seroconversion in a subgroup of patients with chronic hepatitis B. J Clin Virol 2012;54:93-95. doi: 10.1016/j.jcv.2012.01.024. 